\title{
DA COMUNICABILIDADE DO JUÍZO ESTÉTICO
}

\author{
ON THE COMMUNICABILITY OF AESTHETIC JUDGMENT
}

DE LA COMUNICABILIDAD DEL JUICIO ESTÉTICO

Ana Godinho Gil

RESUMO: O objectivo deste artigo é examinar a possibilidade de transmissão do gosto através do juízo estético, o que é certamente um dos maiores desafios do ensino das artes e da educação estética. De onde vem essa dificuldade de comunicação? Quais os factores em jogo? Que experiência estética pode o professor transmitir e quais os limites desse tipo de transferência de sentimentos? Pensamos que ao esclarecer estas questões estamos contribuir para a educação artística e para a procura de práticas concretas a que se poderia chamar "comunicação do gosto". A análise do pensamento de Kant sobre esta matéria revela-se uma peça essencial desse contributo. Analisaremos com a ajuda de Deleuze e Lyotard as noções de sentido comum e senso comum, a comunicabilidade do juízo estético e o pensamento alargado.

PALAVRAS-CHAVE: Senso comum. Sentido comum. Comunicabilidade. Universalidade. Juízo Estético.

ABSTRACT: This article analyzes the possibility of transmission of taste through aesthetic judgment, which is certainly one of the greatest challenges of arts teaching and aesthetic education. From where does come this difficulty of communication? What are the factors involved? Which aesthetic experience can the teacher convey and what are the limits of this type of feelings' transfer? Clarifying these issues, we suppose to contribute to arts education and to find specific practices that could be called "communication of taste." The analysis of Kant's thought on the matter proves to be an essential part of that contributing. Based on Deleuze and Lyotard, we will analyze the notions of meaning in general and common sense, the communicability of aesthetics critique and the broad-minded thought.

Key-words: Common sense. Meaning in general. Communicability. Universality. Aesthetic Judgment.

RESUMEN: El propósito de este artículo es examinar la posibilidad de transmisión del gusto a través de juicio estético, que es sin duda uno de los mayores desafíos de la enseñanza de las artes y la educación estética. ¿De dónde viene esta dificultad de la comunicación? ¿Cuáles son los factores en juego? Esa experiencia estética puede transmitir el maestro y que límites hay en este tipo de transferencia de sentimientos? Creemos que mediante la aclaración de estas cuestiones estamos contribuyendo a la educación artística y la búsqueda de prácticas eficaces que se podrían llamar "comunicación de gusto." El análisis del pensamiento de Kant sobre la materia resulta ser una parte esencial de esa contribución. Analizaremos con la ayuda de Deleuze y Lyotard las nociones de sentido común e de del senso común, en la comunicabilidad del juicio estético y del pensamiento expandido.

Palavras-clave: Senso comum. Sentido comum. Comunicabilidad. Universalidad. Juicio Estético.

\footnotetext{
${ }^{1}$ Professora de Filosofia e Investigadora do Instituto de Filosofia da Nova da Faculdade de Ciências Sociais e Humanas da Universidade Nova de Lisboa, Portugal.

Recebido em: 10/06/2015 - Aceito em: 30/07/2015
} 


\section{SENSO COMUM E SENTIDO COMUM}

A possibilidade de transmitir o gosto através de um juízo é certamente um dos maiores desafios do ensino das artes e da educação estética. De onde vem essa dificuldade de comunicação? Quais os factores em jogo? Que experiência estética pode o docente transmitir e quais os limites desse tipo de transferência de sentimentos? Esclarecer estas questões é contribuir para a educação artística e para a procura de práticas concretas que se poderiam chamar "comunicação do gosto". A análise do pensamento de Kant sobre esta matéria revelase uma peça essencial desse contributo.

No parágrafo 40 da Crítica da Faculdade de Julgar, a possibilidade de um "pensamento alargado" funda-se num sentido comum e este último é concebível enquanto pressuposição da comunicabilidade universal do sentimento.

Embora este sentido não esteja exclusivamente ligado ao juízo do belo, porque pode ser interpretado enquanto pressuposição teórica para a comunicabilidade de todo o conhecimento, será, em princípio, na primeira acepção que se constituirá esta análise.

Trata-se de um sentido que pode ser compreendido enquanto sentido comunitário, quer dizer, de uma certa maneira, enquanto comunidade de sentido que é condição transcendental de toda a comunicação do sentimento e que não se faz através de conceitos, mas através de uma exemplaridade original.

Dir-se-á assim no parágrafo 22, que este sentido é "uma simples norma ideal"(KANT, 1984, p. 79) e o meu juízo de gosto tem por essa razão um "valor exemplar" ou, dito de outro modo, é "um exemplo de uma regra universal que não se pode enunciar" (KANT, 1984, p. 77).

O que assim está essencialmente em causa é o seu estatuto constitutivo ou regulativo, o seu poder enquanto faculdade singular e fora do comum que na verdade se pretende comum, isto é, que deve poder "exigir, no que concerne a unanimidade dos diferentes sujeitos que julgam, uma adesão universal..." (KANT, 1984, p. 79)

Comum, do latim communis, é o que pertence a muitos, que é público e que por isso se pode partilhar com os outros. Diz respeito à pluralidade e supõe num certo sentido uma unanimidade de vozes, pode ser ainda interpretado como bom senso. Por último, podemos defini-lo negativamente, como aquilo que é vulgar, sem importância. Sentido, por seu lado, pode definir-se como um sentir que é ao mesmo tempo sentimento, lugar de uma presença que se pode partilhar se for comum. Sentido é o que dá a ver, dirige o olhar, é direcção. Pode ser também faculdade de sentir em geral; faculdade de experimentar certas sensações, modo de compreender, de julgar um ponto de vista, de orientar, etc. Finalmente se o ligarmos ao primeiro conceito (comum), sentido comum significa, usualmente, faculdade de sentir 
interior, aptidão característica da consciência, sentido de orientação interno (mesmo no sentido biológico). Pode adquirir também o sentido de senso comum, opinião vulgar, ou ainda ser tomado como faculdade do juízo.

Em todas estas acepções, o sentido comum supõe unanimidade, convergência, acordo ou harmonia entre uma pluralidade de sujeitos. Antes de examinarmos as condições - de necessidade e universalidade - a que deve obedecer o juízo de gosto kantiano para que o sentimento que lhe corresponde seja comunicável, cabe referir uma concepção diferente que considera o sentido comum segundo Kant como, precisamente, o que impossibilita o pensamento e, por conseguinte, o "pensamento alargado" que, na Crítica da Faculdade de Julgar, aparece como o que possibilita a comunicação do juízo estético puro: a de Deleuze em Différence et Répétition (DELEUZE, 1968).

Para Deleuze, é o juízo que garante a comunicabilidade entre os sujeitos, pois é ele que assegura a partilha e a hierarquização dos conceitos, quer pelo sentido comum quer pelo bom senso. Neste sentido procura discutir o que lhe parece absolutamente essencial para a constituição do juízo, quer dizer do pensamento.

No capítulo III desse mesmo livro, que trata da imagem do pensamento, são questionados os postulados e pressupostos do pensamento. Deleuze afirma aí a absoluta necessidade do filósofo reflectir e verificar os postulados, pois eles podem constituir-se como impedimento ao próprio acto de pensar. A posição do pensamento enquanto exercício natural de uma faculdade, é a de um sempre recomeçar, numa tarefa infindável de recomeço. O que significa que estão constantemente em causa postulados e pressupostos fundamentais. Um deles é o sentido comum.

De facto, para Deleuze o bom senso e o sentido comum naturais são ainda determinações do pensamento puro, pertencem a um pré-julgar da universalidade e da comunicabilidade porque se apoiam no exercício harmonioso de todas as faculdades relativamente a um mesmo objecto.

Com efeito, "a forma do 'toda a gente sabe...', toda a gente sabe, antes do conceito... significa pensar e ser..." (DELEUZE, 1968, p. 170), é aqui o pressuposto ímplicito que se encontra no sentido comum, enquanto, "cogitatio natura universalis". É esta imagem do pensamento que Deleuze chama imagem dogmática, é este sentido que é necessário discutir. O que podemos discutir então? O "modelo transcendental", quer dizer, o modelo da "recognição" (é aqui que se estabelece a relação com Kant) que se define como o exercício de "concordância das faculdades fundada num sujeito pensante como universal" (DELEUZE, 1968, p. 176) e que reclama para si um princípio subjectivo de colaboração das faculdades que é o sentido comum.

O sentido comum implica sempre uma colaboração das faculdades. A imaginação, o entendimento e a razão colaboram no conhecimento e formam um "sentido comum logico", 
colaboram no modelo prático e aí a razão legisla no sentido comum moral e finalmente no modelo estético as faculdades acedem a um livre jogo que se constitui como o "sentido comum estético". Neste sentido é verdade que as faculdades colaboram em geral para o conhecimento, para a lei moral e para o juízo do belo, mas é também verdade que as fórmulas desta colaboração diferem segundo as condições do que há para conhecer, para julgar moralmente ou para julgar esteticamente (DELEUZE, 1968, p. 179).

É ainda necessário distinguir o que é sentido comum e o que é bom senso. "Se o sentido é norma de identidade, do ponto de vista do eu puro e da forma de um objecto qualquer que lhe corresponda, o bom senso é a norma de partilha do ponto de vista do eu empírico" (DELEUZE, 1968, p. 175).

Nesta discussão o que está em causa é o desacordo de Deleuze com a orientação dada ao modelo da "recognição", que não "rompe com a doxa". E, parece-lhe que a filosofia devia poder "romper com a doxa". É precisamente aqui que surge a oposição a Kant (DELEUZE, 1968, p. 175). Deleuze acusa-o de não renunciar a certos pressupostos implícitos (DELEUZE, 1968, p. 178). Deste modo, seguindo este modelo "ficaremos prisioneiros da doxa" porque fazemos "somente abstracção do seu conteúdo empírico e conservamos o uso das faculdades que lhe correspondem"(DELEUZE, 1968, p. 176). Assim para Deleuze, Kant, longe de arruinar a forma do sentido comum, apenas a multiplicou.

No desenvolvimento do capítulo procura ainda esclarecer melhor o que deixa o pensamento tranquilo e o que o força a pensar. O que força o pensamento a pensar é um "reencontro fundamental", e não uma "recognição". Não há qualquer semelhança com o que se designa por "recognição", pois não é de forma alguma o que se relaciona directamente com os sentidos num exercício natural e mesmo no exercício de outras faculdades no sentido comum, que é pensar. Ao contrário, aquilo a que Deleuze chama "reencontro fundamental" é o que faz realmente nascer a sensibilidade no sentido, é a própria sensibilidade em presença do que não pode ser senão sentido, o encontro com os limites, " é o que é primeiro no pensamento", " é violência" (DELEUZE, 1968, p. 181). E é aí que, para Deleuze, o sentido comum deixa de ser eficiente.

O que não pode ser senão sentido, é aquilo que deixa a alma perplexa, é o que a força a pôr um problema (podem ser "tonalidades afectivas diversas"). De que sentido comum se está então a falar? Se não há sentido comum, se não existem acordos, se não existem harmonias, o que há afinal? Há um "jogo discordante" (ou "acordo discordante"), afirma Deleuze. E o que se pode agora questionar é: se este "jogo discordante" não estará de uma certa maneira relacionado com o que diz Lyotard sobre o sensus communis (LYOTARD, 1987, pp. 3-26). Aí afirma-se que há acordo, há um sentido comum singular, há proporção (essa que acontece no interior do sujeito) e é variável. Diz-se ainda e por isso mesmo que "os acordes não se organizam em linha melódica senão secundariamente" ou então "nem sequer existe regra harmónica" ou ainda "a proporção de que fala Kant não é harmónica" 
(LYOTARD, 1987, p. 15). Na verdade "se é que há sensus communis, ele é exigido por uma outra necessidade, uma outra universalidade..." (LYOTARD, 1987, p.4)

Parece ser impossível para Deleuze a existência deste tipo de acordos, comunidades, harmonias, porque não há um acordo óptimo entre as faculdades, mas, e como já vimos antes, uma espécie de des-acordo, que ele perspectiva numa discórdia, numa espécie de violência a que chamará "jogo discordante". "Cada faculdade saiu dos eixos [est sortie de ses gonds]... cada uma, para si e segundo a sua própria ordem, quebrou a forma do sentido comum que mantinha o elemento empírico na doxa..."(DELEUZE, 1968, p. 184).

Irá mais tarde analisar o que lhe parece ser o caso de excepção em Kant:

\begin{abstract}
Perguntamos por exemplo: o que é que força a sensibilidade a sentir? e o que é que não pode ser senão sentido? E que é o insensível ao mesmo tempo? E esta questão, devemos ainda colocá-la não somente para a memória e o pensamento, mas para a imaginação - há um imaginandum, um $\varphi \alpha v \tau \alpha \sigma \tau \varepsilon o v$, que seja de facto o limite, o impossivel de imaginar? - para a linguagem... e para outras faculdades... até mesmo para faculdades ainda não suspeitas, a descobrir." É precisamente aqui que refere "O caso da imaginação: este caso é o único onde Kant considera uma faculdade liberta da forma de um sentido comum, e descobre para ela um exercício legítimo verdadeiramente 'transcendente'. Com efeito, a imaginação que esquematiza [l'imagination schématisante], na Crítica da Razão Pura, está ainda sob o sentido comum lógico; a imaginação reflexiva, no juízo do belo, está ainda sob o sentido comum estético. Mas com o sublime, a imaginação segundo Kant é forçada, constrangida a enfrentar [affronter] o seu limite próprio, o seu $\varphi \alpha v \tau \alpha \sigma \tau \varepsilon o v$, o seu máximo que é também o inimaginável, o informe ou o disforme na natureza (Crítica da Faculdade de Julgar, §26). E ela transmite o seu constrangimento ao pensamento, por sua vez forçado a pensar o supra-sensível, como fundamento da natureza e da faculdade de pensar: o pensamento e a imaginação entram aqui numa discordância essencial, numa violência reciproca que condiciona um novo tipo de acordo (\$27). De modo que o modelo da recognição ou a forma do sentido comum encontram-se em falta no sublime, em benefício de uma outra concepção do pensamento (§29)" (DELEUZE, 1968, p. 186).
\end{abstract}

O que faz realmente problema aqui é que Deleuze admite a existência de um nexo, uma ordem das faculdades, mas esta ordem não é para ele um acordo ligado ao sentido comum. A sua oposição quanto à possibilidade do sentido comum, funda-se na consideração de que tal sentido não permite a constituição de uma verdadeira génese do pensamento, pois não é bem por um acordo das faculdades mas mais por uma discordância que se concebe o verdadeiro pensamento.

Mas não será possível uma leitura de Kant que identifique no jogo das faculdades, que funda o juízo de gosto, uma discordância essencial, à maneira do que acontece na Analítica do Sublime? 
Neste caso, o sensus communis não reforçaria a doxa, mas antes se constituiria naquilo que Kant exige para o juízo de gosto, isto é, que se tome em consideração "todos os outros juízos de gosto possiveis": não será assim a própria diferença com os outros que fundamenta a pretensão à universalidade?

\section{A NECESSIDADE SUBJECTIVA DO SENTIDO COMUM}

O sentido comum visto segundo a perspectiva anterior, apresenta, de facto, dificuldades. Na verdade a questão da comunicabilidade do sentimento no juízo estético não é pacífica e mesmo o texto kantiano não é sempre claro, nem sempre trata esta problemática do mesmo modo em todos os lugares. Estabelecem-se por exemplo, distinções fundamentais na Crítica da Faculdade de Julgar, nos $\S \S 18,19,20,21,22$ e 40.

Logo no parágrafo 18, refere-se o carácter da necessidade, dizendo que é pensado num juízo estético como neces $\neg$ sidade que "só pode ser denominada exemplar, isto é uma necessidade de adesão de todos a um juízo que é considerado como exem $\neg$ plo de uma regra universal que não se pode enunciar" (KANT, 1984, p. 77).

Ora a necessidade de adesão de todos é um facto no juízo do belo e determina-se subjectivamente uma vez que se procura ganhar a adesão de todos, numa espécie de promessa ou comprometimento desinteressado. Do ponto de vista cognitivo é incerta esta procura, só pode acontecer de uma certa maneira porque na realidade, diz Kant: "se tem para isso um fundamento que é comum a todos" (KANT, 1984, p. 77). A existência deste fundo comum não é absolutamente trans $\neg$ parente e é por isso mesmo que está em causa. Será este fundamento comum a todos, uma faculdade, um simples princípio, um sentimento ou um ponto de vista essencial, que liga todos os sujeitos da comunidade humana numa espécie de "lugar público"? Ou será como julga Lyotard a sede de uma "capacidade de reflectir pura" que é uma "capacidade do espírito"?

Especificamente no parágrafo 20, Kant chama "princípio comum a todos" àquele princípio subjectivo, que supostamente nos permite partilhar os nossos juízos com todos os outros. Supõe-se que é possível partilhar a multiplicidade de pontos de vista, quer dizer, que a possibilidade de partilhar o mundo com os outros membros da comunidade humana se funda num sentido subjectivo e é por ele que reencontramos o outro e o reconhecemos. Parece assim possível reconhecer a existência de um "lugar público", de pluralidade, pensar na universalidade e possível adesão dos outros aos nossos juízos particulares e vice-versa. A partilha implica debate, discussão e con-fronto, não é uma simples aceitação tácita dos pontos de vista dos outros e dos nossos próprios, justamente, exige que tal princípio exista mesmo e que não seja confundido com o senso comum vulgar, como o próprio Kant esclarece mais adiante, no parágrafo 40. 
É um facto incontestável que, quando julgamos, pretendemos a adesão dos outros aos nossos juízos, nas comparações, nas distinções, nos confrontos e é propriamente por isso que os queremos persuadir. Os resultados são tentativas de convencimento desinteressado ou não. Quando estamos no domínio do conhecimento, este convencimento faz-se por meio de provas, no juízo estético já não é o caso. Não há aqui qualquer determinação objectiva, pois o universal não é dado conceptulmente; o juízo estético é por sua própria definição subjectivo.

Se os juízos de que estamos a falar se constituissem por intermédio de princípios objectivos determinados, não haveria necessidade de procurar o assentimento dos outros, pois ele seria determinado conceptualmente, objectivamente. Se por outro lado não existisse nenhum princípio, "não ocorreria ao espírito de ninguém que eles tivessem alguma necessidade"(KANT, 1984, p. 78).

Então, para terminar o seu raciocínio, Kant afirma: "Logo, eles têm que possuir um princípio subjectivo, o qual determine, somente através do senti-mento e não por conceito, ainda que de maneira universalmente válida, o que apraz ou desapraz.." (KANT, 1984, p. 78).

Mas já antes no parágrafo 8 se podia compreender esta ideia fundamental, quando Kant fazia notar que:

\begin{abstract}
uma universalidade que não se baseia em conceitos de objectos (ainda que somente empíricos) não é absolutamente lógica, mas estética, quer dizer, que ela não contém nenhuma quantidade objectiva do juízo, mas somente uma quantidade subjectiva; para a designar utilizo a expressão valor comum <Gemeingültigkeit>, que indica para cada sujeito o valor da relação de uma representação ao sentimento de prazer e desprazer e não à faculdade de conhecer (...) Ora, um juízo objectivo de valor universal é também sempre subjectivo; dito de outro modo, quando o juízo tem um valor para tudo o que está compreendido sob um conceito dado, ele possui igualmente um valor para todos os que se representam um objecto por este conceito. Em compensação não podemos concluir de uma universalidade subjectiva, isto é, estética, que não se baseia em nenhum conceito, uma universalidade lógica; com efeito este género de juízos não remete absolutamente ao objecto. Tanto mais que a universalidade estética, que é conferida a um juízo, também pode ser de um género particular... (KANT, 1984, p. 58).
\end{abstract}

Quer então dizer que temos a pretensão de atribuir a um sentimento singular e pessoal um valor universal, isto é, afirmamos a sua verdade para todo o outro sujeito? De facto, o sentimento que aqui está em questão tem de ter alguma ligação às faculdades, fontes de universalidade. Assim, embora o juízo seja sem conceito e o mesmo é dizer que lhe parece faltar a regra porque não a encontramos, também não encontramos o objecto. $\mathrm{O}$ facto é que aparece nele uma exigência de objectividade e universalidade, uma vez que se refere à "esfera inteira dos que julgam". De que natureza é, finalmente, este princípio subjectivo? Que sentimento é este?

Eventualmente poderá, diz Kant, ser considerado como um sentido comum [gemeinsinn] e não, concerteza, como um senso comum [gemeiner Verstand]. É um sentido originário, a priori, que diz respeito a toda a humanidade, que Kant está aqui a considerar? 
No final do parágrafo 20, a relação em causa é pensada de maneira que o sentido comum é considerado como pressuposição fundamental para a possibilidade dos juízos de gosto e provavelmente também para a possibili-dade de acordo com todos os outros sujeitos. Não é um sentido externo "mas o efeito decorrente do jogo livre das nossas faculdades de conhecimento" (KANT, 1984, p. 78). Podemos então supor que este "efeito" é uma espécie de sentido interno, o que por outras palavras significa que os "acordos", as "proporções", as "harmonias" nascem no interior do su-jeito e multiplicam-se quando se encontram com os outros sujeitos da comunidade humana.

\section{A COMUNICABILIDADE UNIVERSAL DO CONHECIMENTO E DO SENTIMENTO}

A "concordância com o objecto", se entendermos por concordância, acordo ou harmonia, é propriamente conhecimento e tem necessidade de ser comunicável universalmente. Sobre isto trata Kant no parágrafo 21, considerando que, se os conhecimentos e juízos devem poder comunicar-se, também o "estado de espírito" tem de poder comunicar-se universalmente. "Estado de espírito" é aqui a disposição das faculdades (movimento) de conhecimento para um conhecimento em geral e também a proporção que é diferente em cada caso e de acordo com a diversidade dos objectos que estão em causa.

Relativamente ao ponto anterior, a pretensão kantiana alarga-se, pois as razões que o levam a pressupor um sentido comum na comunicabilidade de um sentimento parecem estar também justificadas no caso do conhecimento, quando diz: "assim este poderá ser admitido com razão, e na verdade sem neste caso se apoiar em observações psicológicas, mas como a condição necessária da comunicabilidade universal do nosso conhecimento, a qual é pressuposta em toda a lógica e em todo o princípio dos conhecimentos que não seja céptico" (KANT, 1984, p. 79).

Podemos compreender, na verdade, razões suficientes para a legitimação em causa, mas uma condição só é legítima se de facto tiver um princípio que a autorize de alguma maneira. O princípio em causa é subjectivo, não pode ser considerado determinante porque resiste à conceptualização, isto é, opera na ausência de regras, e contudo, diz Kant, é universalmente válido. Nestas condições, "podemos com algum fundamento pressupor um sentido comum?"

Por este sentido, este sensus, diz Lyotard "somos transportados para o mais humilde, para o mais 'comum' do juízo, num 'estado de espírito' que não deve nada ainda (nada ainda ou já mais nada) às intrigas do conhecimento"(LYOTARD, 1987, p.6). Não há neste mais "comum" do juízo determinação de regularidades como na lei cognitiva. Que há então? Há esta condição subjectiva do conhecer sem a qual o conhecimento não se pode comunicar. Não é, como já tinha dito antes, um sentido externo mas é um "efeito resultante do livre jogo das 
faculdades de conhecer".

A subjectividade aqui é "relativa às meras relações das faculdades entre si no sujeito", quer dizer que a imaginação e o entendimento estão juntos de uma certa maneira. É por conseguinte este "jogo" que determina o sentimento de prazer. Pode já esboçar-se uma reposta à pergunta: este sentido comum, enquanto pressuposto fundamental não é somente uma mera "validade comum", mas constitui-se enquanto "validade exemplar", porque não se encontra a regra. Mas ao mesmo tempo exige-se nesta singularidade uma forma de universalidade. De que se trata?

De uma proporção. É absolutamente necessária a existência de uma proporção, que seja a mais propícia possível para as faculdades do espírito com vista ao conhecimento em geral. Esta disposição, este acordo "não pode ser determinado de outro modo senão pelo sentimento (não segundo conceitos)" (KANT, 1984, p. 79). A comunicabilidade do juízo de gosto parece radicar neste sentimento, que é puramente subjectivo e pretende por esta proporção, ser universalmente comunicável, a saber, um sentimento de prazer puro, que não é mais do que "animação", "jogo livre".

A imaginação tem aqui um poder fundamental, pois é ela segundo a compreensão de Kant que põe em movimento a outra faculdade que é o entendimento. Este último abdica da sua função específica, quer dizer, não submete a imaginação aos seus domínios, mas deixa-a num movimento de alteridade. Aqui a imaginação é livre de tal modo que o seu movimento resulta num estado de espírito que se quer comunicar universalmente. Porque há este "apelo" às faculdades de conhecer, num esforço de encontrar o universal que falta, a relação singular ou disposição do entendimento e da imaginação designa-se aqui, indeterminada. Que diz Lyotard a este respeito?

Ora julga-se em toda a parte, em todos os domínios, e em todos há sensus em jogo, um estado de espírito, mesmo quando ele conhece e quer. (...) Há todavia, e isso é exigido transcendentalmente, um sentimento de prazer, uma euforia, associada ao conhecimento, ou seja à cooperação da sensibilidade e do entendimento requerida pelo conhecimento, uma euforia subjectiva de subsunção de uma intuição sob um conceito, que garante a objectividade. (...) a estética [porque tem outras pretensões] não é susceptível de nenhum interesse. (...) certamente porque o sentimento estético não é mediatizado, por conceito ou ideia, e porque não obedece ao impulso que move o conceito (...) Não anuncia nada" (LYOTARD, 1987, p. 9).

É "puro movimento que compara", uma "música interior", como atrás já se disse, uma proporção variável. Como explica mais adiante Lyotard: "a proporção de que fala Kant não é harmónica, arquitectural, porque ela não é objecto de conceito. É uma proporção de timbres, de cromatismos, de luzes vocais" (LYOTARD, 1987, p. 15). É uma proporção sem regularidades mas "a mais apropriada".

Falta ainda indicar a conclusão de Lyotard: "segue-se que este acordo, não ouso dizer, e não se deve dizê-lo, perfeito, mas belo, ou de belo, ou em beleza, ex-celente, como o 
conhecimento que é a sua ocasião, é a priori universalmente comunicável. E como o sensus communis é pressuposto necessariamente na comunicabilidade deste acordo, uma vez que este sensus não é mais do que o nome atribuído à 'sede' onde se tramam estas proporções, incluindo a excelente, é enfim razoável admitir o sensus communis" (LYOTARD, 1987, p. 16).

Pelas razões já apresentadas, se podemos pensar que os conhecimentos se comunicam universalmente, podemos também pensar que o estado de espírito tem de poder também comunicar-se, pois na verdade a pressuposição de um sentido comum, como condição subjectiva fundamental, interfere de modo decisivo na comunicabilidade in $\neg$ tersubjectiva. A ideia fundamental que parece nortear desde o ínicio o ponto de vista kantiano é, de facto, a existência de outros sujeitos com algo comum (possivelmente uma espécie de faculdade vital), uma espécie de "faculdade" intersubjectiva que funda a subjectividade.

A necessidade de adesão universal, que é concebida num juízo de gosto, é como já vimos uma necessidade subjectiva e é provável que sob a pressuposição de um sentido comum seja representada como objectiva (este é o problema do parágrafo 22).

Ao afirmar que um objecto é belo, não estamos a dizer que é uma propriedade sua, apesar de tal afirmação surgir directamente da sua apreensão. Não sabemos nada dele, mas porque temos uma certa experiência (estética) queremos comunicar algo que sentimos. Procuramos de certo modo representar o que não se apresenta. E se assim é, o que pretendemos na verdade é a adesão dos outros (de todos!) sujeitos possíveis, não reais, não empíricos, para algo do qual nada sabemos e neste caso "eles" "devem" concordar com o nosso juízo de gosto. O que significa que é uma "validade universal" peculiar que é pretendida.

A posição das dificuldades, nesta presunção, encontra-se no facto do fundamento em questão não residir de forma alguma no objecto mas sim na forma pura, quer dizer, não se produz aqui nenhuma determinação objectiva, ou empírica, ao invés trata-se de uma determinação não conceptual, melhor dizendo uma indeterminação que é condição sine qua non para um verdadeiro juízo de gosto.

Ora o nosso juízo só pode fundar-se no sentimento que é um sentido comunitário <gemeinschaftliches> e não um sentido privado. É verdade que este sentido, não pode fundar-se na experiência uma vez que, como atrás foi dito, "ele quer dar direito a juízos que contêm um dever" (KANT, 1984, p. 79), quer ser comunicável. Desta explicitação resulta que ele aqui é como que um exemplo do juízo de gosto e portanto compreendido enquanto validade exemplar: "ele não diz que cada um irá concordar com o nosso juízo, mas que cada um deve concordar com este. Deste modo o sentido comum, do qual dou como exemplo o meu juízo de gosto, conferindo-lhe por esta razão um valor exemplar, é uma simples norma ideal. Pressupondo este podemos com razão estabelecer como regra para cada um..." (KANT, 1984, p. 79). 
Cada um é aqui pura possibilidade, distinta do empírico e do privado, é aqui a unanimidade. Juízo designa aqui qualquer coisa, não há regra, mas não é por isso que se gera o caos. Não há regra mas há "norma", que é mais uma maneira de não se conhecer, um modo de constituição do fundamento da criação. Trata-se da apresentação de uma ausência de regra por onde na verdade se suscita, se exaltam, se animam as faculdades, solicitando o livre jogo pelo qual se sondam poderes, faculdades de sentir. Abrem-se campos, uma cadeia infinita de possibilidades. Por aqui se propõe, se mostra, se sabe, sente e tem em conta as relações de alteridade que são o modo de "representação de todo o outro homem". Como é na verdade isto possível?

\section{A POSSIBILIDADE DO PENSAMENTO ALARGADO. NOTAS FINAIS.}

Trata-se aqui de elucidar, de algum modo, o que Kant finalmente no parágrafo 40 diz a respeito do sentido comum. Este sentido apresentar-se-á como princípio de comunicabilidade entre um sujeito e outro sujeito, visando uma universalidade não determinada por conceitos. Liga-se ao que há de mais inicial (uma génese do pensamento), a saber, a própria subjectividade humana. Mostra-se então como a condição de possibilidade da intersubjectividade e é neste sentido que é verdadeiramente a condição transcendental da experiência estética. Mas, como?

Logo no início do parágrafo, Kant, esclarece-nos acerca do que compreende que é um sentido marcando bem a distinção relativamente ao "sentimento humano comum". "O entendimento comum, quando não é senão um entendimento são (ainda não cultivado), é considerado como a qualidade inferior, que podemos sempre esperar daquele que tem o nome de homem, (...) tem então a honra humilhante de ser designado pelo nome de sentido comum (sensus communis) e de tal modo que sob este termo comum (...) compreendemos o vulgar, que se encontra por todo o lado e que a posse não é absolutamente um mérito ou um previlégio" (KANT, 1984, p. 127).

Decorre desta última análise, sem dúvida, que não é deste sentido que se trata. É de um sentido público, (de uma maneira de julgar que tem em consideração o "modo de representação de todo o outro") que é aqui verdadeiramente o caso. A exigência fundamental deste parágrafo diz respeito à comunidade. Colocarmo-nos no lugar do outro, de todo o outro, é fundamental para a pretensão do juízo do gosto, para a pretensão de adesão universal dos outros aos nossos próprios juízos, como de resto já tínhamos visto anteriormente.

Trata-se realmente de fazer seu o ponto de vista do outro, pois quando nos colocamos no lugar do outro, é como se simulássemos o seu pensamento, o seu sentimento. É por uma "disposição" inédita que se mostra isto. Pode ser possível que ocorra assim porque há para isso uma "região", um "lugar"; porque, de uma certa maneira, se faz uma "pausa" de pensamento, suspende-se a adesão ao que se quer conhecer, não há conceito. Há uma 
diferença essencial. Inicia-se uma transformação que se des-envolve num saber que não é conhecimento, é um saber outro. Pode na verdade perguntar-se imediatamente para quê passarmos por essa "prova de fogo"?

Numa primeira implicação, negativa, tal prova significará um esquecimento de si próprio, isto é, uma experiência de alteridade, curiosamente de distanciamento relativamente a si próprio.

Em segundo, ainda que possamos, sempre, permanecer na nossa posição, devemos poder olhar o outro. Pois só por esta consideração, podemos com justeza entender a própria exigência de compreensão, uma vez que mesmo não saindo do nosso próprio ponto de vista queremos muitas vezes converter o outro, ao nosso. Ora o que estamos a fazer neste caso é a pretender que ele faça aquilo que nós não queremos fazer. Portanto, mesmo que a nossa posição se mantenha firme é fundamental compreender o ponto de vista do outro, e isso significa, já, que a nossa posição não pode ser tão firme assim ou então estamos perante aquilo que Kant, na Crítica da Razão Pura em B173, define como "estupidez": "A carência de faculdade de julgar é propriamente aquilo que se designa por estupidez e para seme-lhante enfermidade não há remédio. Uma cabeça obtusa ou limitada, à qual apenas falte o grau conveniente de entendimento e de conceitos que lhe são próprios, pode muito bem estar equipada para o estudo e alcançar mesmo a erudição. Mas, como há ainda, habitualmente, falha na faculdade de julgar..., não é raro encontrar homens muito eruditos que habitualmente deixam ver, no curso da sua ciência, esse defeito irreparável."

Por conseguinte, parece que o único modo de tornar compreensível a posição do outro, é considerá-lo no horizonte do nosso próprio ponto de vista, o que significa a possibilidade de nos transpormos para o lugar do outro, eliminando de certa forma as limitações materiais e acidentais. Tocamos de facto num ponto onde há pouco a esperar de argumentos lógicos.

Assim, este sentido de comunidade surge em Kant, neste parágrafo 40, como se fosse a própria faculdade do gosto: "...digo que podemos dar com maior direito o nome de sensus communis ao gosto que ao bom senso <der gesunde Verstand> e que a faculdade estética de julgar, mais que aquela que é intelectual, merece o nome de sentido comum a todos <eines gemeinschaftlichen Sinnes>2 se queremos mesmo chamar sentido ao efeito da simples reflexão sobre o espírito; entendemos então com efeito por sentido o sentimento de prazer" (KANT, 1984, p. 128).

Numa nota a passagem que acabamos de citar, Kant refere: "pode-se designar o gosto como sensus communis aestheticus e o entendimento humano comum como sensus communis logicus", sublinhando assim o aspecto distinto e essencial desta faculdade. 
Da suposição, de que existe um outro "igual" a mim a quem posso compreender e por quem sou em última instância afectado, decorre a possibilidade de comunicar um sentimento (prazer), de constituir portanto um ponto de vista universalmente compartilhável. E quando se constitui?

"Não é senão quando a imaginação na sua liberdade acorda o entendimento e que este incita sem conceito a imaginação a um jogo regular, que a representação se comunica, não como pensamento, mas como sentimento interior de um estado final de espírito" (KANT, 1984, p. 129). Sublinhe-se ainda que, se o sentido comum é aqui o sensus communis, ele é então essencialmente o gosto e este último é a "faculdade de julgar a priori" a comunicabilidade universal dos sentimentos, então é o sentido comum a pressuposição fundamental da comunicabilidade universal entre os sujeitos.

Para nos elucidar melhor acerca das condições de possibilidade do pensamento alargado, quer dizer, dos princípios que orientam este ponto de vista universal que analisamos à pouco, Kant refere-se a três máximas que diz serem do entendimento humano comum: "1 Pensar por si mesmo; 2 - Pensar no lugar de todo o outro; 3 - Pensar sempre de acordo consigo próprio" (KANT, 1984, p. 127).

A segunda máxima, que nos interessa imediatamente, traduz-se numa "maneira de pensar alargada". Só um homem de "espírito aberto", como diz Kant, pode "refletir sobre o seu próprio juízo a partir de um ponto de vista universal (que ele não pode determinar senão quando se coloca no ponto de vista do outro)."[36]

Os acontecimentos que forçam o pensamento a reflectir, são aqueles que deixam a alma perplexa, são os que rompem com o habitual, são os que levam à reflexão. É justamente uma experiência de alteridade que faz despertar a "alma", forçando-a a procurar, a reflectir. É uma experiência de transformação que passa pelo "outro" e se abre para um infinito, num ponto de convergência de todos os homens e onde se podem realizar todas as possibilidades de sentido, de gosto. Reconhece-se de verdade aqui, a ne-cessidade de encontrar um ponto de vista que podia ser o do primeiro sujeito, que é um sujeito "em estado nascente".

Deste parêntesis pode concluir-se uma conexão com a segunda máxima kantiana. A possibilidade de partilharmos o mundo com os outros membros da comunidade humana, julgando o que há de comum, significa, o reconhecimento do outro como lugar fundamental e, a necessidade de um espaço público de partilha. Este poder de tornar presente, ou melhor de trazer à presença o que está ausente, esta capacidade de ser outro, é um lugar ideal onde se desvela a própria natureza do mundo humano. Num certo sentido, Kant dá-lhe forma quando exige um princípio intersubjectivo que é um sentido antes dos conceitos e, por isso mesmo, não mais do que um sentimento puro e comum. É "público", enquanto poder do espírito, enquanto faculdade proporcionada, isto é, mais apropriada, que só pode mostrar-se através da exemplaridade. 
O que por último o sentido comum parece poder fazer é orientar o juízo de cada um para a possibilidade do pensamento alargado, escapando-se assim "à ilusão que resulta de condições subjectivas e particulares e que podem facilmente ser tomadas por objectivas, o que exerceria uma influência nefasta sobre o juízo (KANT, 1984, p. 127).

Numa última palavra, este movimento que é sentido antes dos conceitos é "puro movimento que compara".

\section{REFERÊNCIAS}

CHÉDIN, Olivier. Sur l'Esthétique de Kant - et la théorie critique de la représentation. Paris: Vrin, 1982.

DELEUZE, Gilles. Différence et Répétition. Paris: P.U.F., 1968.

DELEUZE, Gilles. La Philosophie Critique de Kant. Paris: P.U.F., 1963.

LYOTARD, Jean-François. Sensus Communis. Análise, n. 6, p. 3-26.

KANT, Immanuel. Crítica da Razão Pura. Lisboa: Gulbenkian, 1985.

KANT, Immanuel. Critique de la Faculté de Juger. Paris: Vrin, 1984.

GUYER, Paul. Kant and the Claims of Taste. Harvard: Harvard Univ. Press, 1979.

\section{Como citar este documento:}

